\title{
Stepwise Oxidation of Three Communicating Metal Centres: Electrochemistry of Trinuclear Trindenyl Complexes of Manganese or Rhodium
}

\author{
Rainer Winter, ${ }^{a}$ David T. Pierce, a William E. Geiger* a and Thomas J. Lynch ${ }^{b}$ \\ a Department of Chemistry, University of Vermont, Burlington, VT 05405, USA \\ b Department of Chemistry, University of Nevada at Reno, Reno, NE 89557, USA
}

Trinuclear manganese or rhodium complexes of the trindenyl (Td) ligand undergo three separate $1 \mathrm{e}^{-}$-oxidation reactions, with an abnormally large separation in potentials between the second and third oxidations of $\left[\mathrm{Td}\left\{\mathrm{Rh}_{3}(\operatorname{cod})_{3}\right\}\right]$.

Metal complexes of the trindenyl trianion $\mathbf{1}^{1}$ (Td) offer an opportunity to study the properties of a high density of metal centres grafted onto a hydrocarbon backbone. Since the rigidity of the hydrocarbon minimizes the geometric distortions that can occur upon oxidation or reduction, these complexes are attractive models with which to probe metalmetal interactions over known distances in mixed-valent systems. We now report the first electrochemical results on the trinuclear trindenyl complexes $\left[\mathrm{Td}(\mathrm{ML})_{3}\right] 2^{2}[\mathrm{ML}=$ $\left.\mathrm{Mn}(\mathrm{CO})_{3}\right]$ and $\mathbf{3}^{3}[\mathrm{ML}=\mathrm{Rh}(\operatorname{cod})$, cod $=$ cycloocta-1,5diene]. Although both systems display three oxidations, $\mathbf{3}$ is particularly informative in showing three successive diffusioncontrolled one-electron processes. A surprisingly large difference in formal potentials is observed for the $3^{+/ 2+}$ and $3^{2+13+}$ couples.

Cyclic voltammetry (CV) scans of 2 in $\mathrm{CH}_{2} \mathrm{Cl}_{2} \dagger$ show two $1 \mathrm{e}^{-}$anodic waves (I and II, Fig. 1) along with their cathodic counterparts, III and IV. Waves I and IV comprise the reversible couple $2-2^{+}, E^{\circ}=+0.77 \mathrm{~V} v s$. $\mathrm{Fc}_{-}-\mathrm{Fc}^{+}, \dagger$ consistent with expectations for an analogue of $\mathrm{CpMn}(\mathrm{CO})_{3}{ }^{4}$ The one-electron nature of this process was confirmed by coulometry. Wave III is a cathodic stripping peak, showing that the dication, $2^{2+}$, produced in wave II precipitates on the $\mathrm{Pt}$ electrode. An estimate of the formal potential of $\mathbf{2}^{+-2^{2+}}$ is obtained from the average of II and III: $+0.98 \mathrm{~V}$. A third anodic wave with $E_{\mathrm{p}} c a .+1.2 \mathrm{~V}$ is of uncertain significance, owing to the problem of precipitation of the dication.

With 3 , the polycations are more soluble and all three $1 \mathrm{e}^{-}$ couples are accessible. $\mathrm{ML}=\mathrm{Rh}(\mathrm{cod})$ is perhaps an unlikely candidate for reversible electrochemical 'tag' on the trindenyl ligand, since the oxidation of the mononuclear analogue $[\mathrm{CpRh}(\mathrm{cod})]$ is irreversible in the same medium. ${ }^{5}$ Oxidation of 3 proceeds, nevertheless, in three well-defined and reversible $\$ 1 \mathrm{e}^{-}$steps (Fig. 2) with formal potentials of $-0.33,-0.16$ and $+0.43 \mathrm{~V}$, respectively, for the couples $3-3^{+}, 3^{+}-\mathbf{3}^{2+}$ and $3^{2+}-3^{3+}$ [eqn. (1)]. Bulk coulometry has confirmed the reaction stoichiometry, and an EPR spectrum of $3+$ in $\mathrm{CH}_{2} \mathrm{Cl}_{2}$ has been obtained $\left[\langle g\rangle=2.0492\right.$ (fluid); $g_{1}=2.0883, g_{2}=$ $2.0579, g_{3}=2.0024$ (frozen)]

$$
\begin{aligned}
{\left[\mathrm{Td}\left\{\mathrm{Rh}_{3}(\operatorname{cod})_{3}\right\}\right] } & \stackrel{-\mathrm{e}^{-}}{\rightleftharpoons}\left[\mathrm{Td}\left\{\mathrm{Rh}_{3}(\operatorname{cod})_{3}\right\}\right]^{+} \\
& \stackrel{-\mathrm{e}^{-}}{\rightleftharpoons}\left[\mathrm{Td}\left\{\mathrm{Rh}_{3}(\operatorname{cod})_{3}\right\}\right]^{2+} \\
& \stackrel{-\mathrm{e}^{-}}{\rightleftharpoons}\left[\mathrm{Td}\left\{\mathrm{Rh}_{3}(\operatorname{cod})_{3}\right\}\right]^{3+}
\end{aligned}
$$

The magnitude of the separations between formal potentials in redox processes of homomultinuclear complexes is one indication of the degree of electronic interactions between the metals. ${ }^{6}$ The separation of $\mathbf{3}^{-3^{+}}$and $\mathbf{3}^{+}-\mathbf{3}^{2+}(170 \mathrm{mV})$ is typical of Class II $^{7} \mathrm{M}-\mathrm{M}$ interactions, i.e. involving trapped-

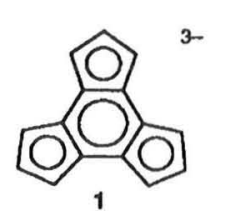

1

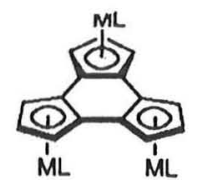

$2 \mathrm{ML}=\mathrm{Mn}(\mathrm{CO})_{3}$ $2 \mathrm{ML}=\mathrm{Mn}(\mathrm{CO})_{3}$
$3 \mathrm{ML}=\mathrm{Rh}(\mathrm{cod})$ valence systems. ${ }^{8}$ The much larger separation between $3^{+}-3^{2+}$ and $3^{2+-3^{3+}}(550 \mathrm{mV})$ is more typical of Class III (totally delocalized) systems. 9 Whether this pattern of potential separations is unique for 3 and whether it arises from variations in delocalization among the metals or from other sources such as coulombic interactions remain to be shown. Given the synthetic versatility of cyclopentadienyl-based ligand systems, there are good opportunities to answer questions about metal-metal interactions by coordinating transition metal units with suitable spectroscopic labels to Td, and efforts are proceeding along these lines.

This work was generously supported at University of Vermont by the National Science Foundation (CHE 91-

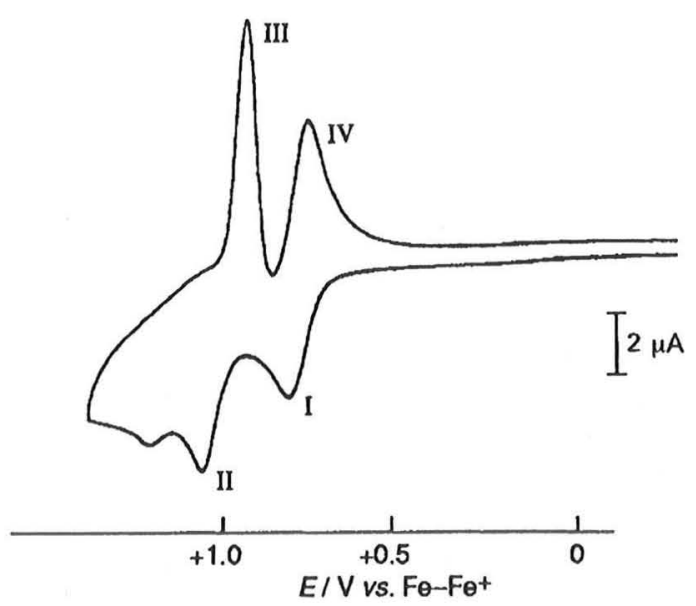

Fig. $1 \mathrm{CV}$ scan of $0.44 \mathrm{mmol} \mathrm{dm}^{-3} 2$ in $\mathrm{CH}_{2} \mathrm{Cl}_{2}-0.1 \mathrm{~mol} \mathrm{dm}^{-3}$ $\left[\mathrm{NBu}_{4}\right]\left[\mathrm{PF}_{6}\right]$ at $\mathrm{Pt}, T=270 \mathrm{~K}, v=0.1 \mathrm{~V} \mathrm{~s}^{-1}$

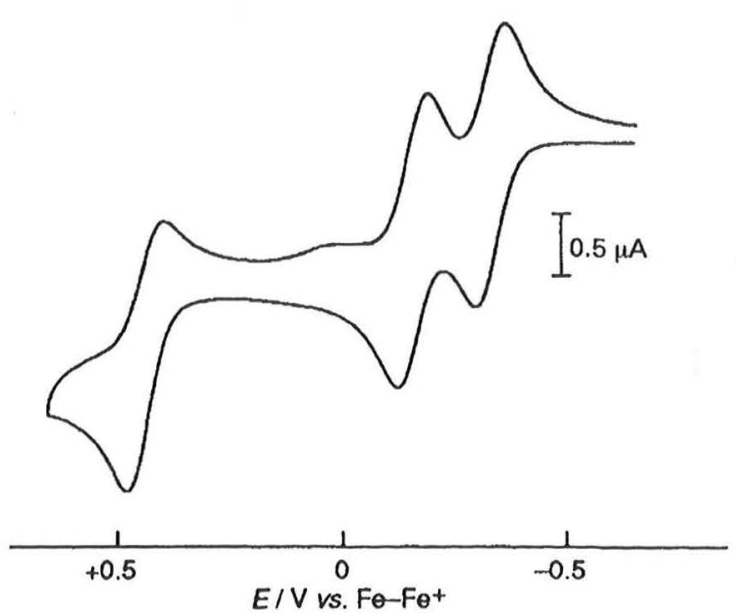

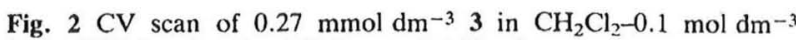
$\left[\mathrm{NBu}_{4}\right]\left[\mathrm{PF}_{6}\right]$ at $\mathrm{Pt}, T=260 \mathrm{~K}, v=0.1 \mathrm{~V} \mathrm{~s}^{-1}$ 
16332) and by Deutsche Forschungsgemeinschaft (grant for R. W.). We thank M. C. Helvenston for a sample of 2 .

\section{Footnotes}

$\dagger$ Other electrochemical conditions: $0.1 \mathrm{~mol} \mathrm{dm}^{-3}\left[\mathrm{NBu}_{4}\right]\left[\mathrm{PF}_{6}\right], \mathrm{Pt}$ working electrode, potentials referenced to ferrocene-ferrocenium, which had a potential of $+0.48 \mathrm{~V} v s$. SCE in this medium. $T=270 \mathrm{~K}$ for $2,260 \mathrm{~K}$ for 3 .

$\ddagger$ The $3^{2+}-3^{3+}$ couple required $v>0.2 V^{-1}$ for complete chemical reversibility.

\section{References}

1 T. J. Katz and W. Slusarek, J. Am. Chem. Soc., 1980, 102, 1058. 2 T. J. Lynch, M. C. Helvenston, A. L. Rheingold and D. L. Staley, Organometallics, 1989, 8, 1959.

3 H. Bang, T. J. Lynch and F. Basolc, Organometallics, 1992, 11, 40 $4 \mathrm{~J}$. W. Hershberger, R. J. Klingler and J. K. Kochi, J. Am. Chem. Soc., 1983, 105, 61; N. G. Connelly and M. D. Kitchen, J. Chem. Soc., Dalton Trans., 1977, 931.

5 Unpublished observations: M. D. Kitchen and N. G. Connelly, University of Bristol, 1975; T. T. Chin and W. E. Geiger University of Vermont, 1993.

6 D. E. Richardson and H. Taube, Coord. Chem. Rev., 1984, 60, 107.

7 M. B. Robin and P. Day, Adv. Inorg. Chem. Radiochem., 1967, 10, 247.

8 A. M. Gilbert, T. J. Katz, W. E. Geiger, M. P. Robben and A. L. Rheingold, J. Am. Chem. Soc., 1993, 115, 3199 and references therein.

9 M.-T. Lee, B. M. Foxman and M. Rosenblum, Organometallics, $1985,4,539$. 